\title{
Childhood abuse and borderline personality disorder features in Chinese undergraduates: the role of self-esteem and resilience
}

Guo-Die Xie ${ }^{1,2+}$, Jun-Jie Chang ${ }^{1+}$, Meng-Yuan Yuan', Geng-Fu Wang ${ }^{1}$, Yang He${ }^{1}$, Shan-Shan Chen ${ }^{1}$ and $\mathrm{Pu}-\mathrm{Yu} \mathrm{Su}^{1,3,4^{*}}$

\begin{abstract}
Background: Although childhood abuse is considered to be related to borderline personality disorder (BPD), few studies have elaborated on the mediating role of self-esteem and resilience in it. Thus, the present study aimed to explore the potential mediating role of resilience and self-esteem between childhood abuse and BPD.

Methods: This cross-sectional study was conducted with 4034 college students in Anhui Province, China. Participants were asked to complete Chinese versions of the following instruments: Childhood Trauma Questionnaire-Short Form (CTQ-SF), Mclean Screening Instrument for Borderline Personality Disorder (MSI-BPD), Connor-Davidson Resilience Scale (CD-RISC), and Rosenberg Self-Esteem Scale (RSES). Structural equation modeling (SEM) was used to test the mediation effects.

Results: Resilience and self-esteem were found to be mediators of all three types of childhood abuse (emotional abuse, physical abuse and sexual abuse) when the types were examined separately; however, when all three types of childhood abuse were entered into the model simultaneously, neither the indirect effects nor direct effects of physical abuse or sexual abuse were found to be significant, only the association between emotional abuse and BPD features was partially mediated by resilience and self-esteem.
\end{abstract}

Conclusions: Self-esteem and resilience mediate the links between childhood abuse and BPD features, and emotional abuse is uniquely associated with BPD features.

Keywords: Childhood abuse, Self-esteem, Resilience, Borderline personality disorder, Mediation effects, Structural equation model

\footnotetext{
*Correspondence: supuyu@ahmu.edu.cn

${ }^{\dagger}$ Guo-Die Xie and Jun-Jie Chang contributed equally to this work.

'Department of Maternal, Child and Adolescent Health, School of Public

Health, Anhui Medical University, No.81 Meishan Road, Hefei 230032, Anhui,

China

${ }^{3}$ Key Laboratory of Population Health Across Life Cycle (Anhui Medical

University), Ministry of Education of the People's Republic of China, No 81 Meishan Road, Hefei 230032, Anhui, China

Full list of author information is available at the end of the article
}

C C The Author(s). 2021 Open Access This article is licensed under a Creative Commons Attribution 4.0 International License, which permits use, sharing, adaptation, distribution and reproduction in any medium or format, as long as you give appropriate credit to the original author(s) and the source, provide a link to the Creative Commons licence, and indicate if changes were made. The images or other third party material in this article are included in the article's Creative Commons. licence, unless indicated otherwise in a credit line to the material. If material is not included in the article's Creative Commons licence and your intended use is not permitted by statutory regulation or exceeds the permitted use, you will need to obtain permission directly from the copyright holder. To view a copy of this licence, visit http://creativecommons.org/licenses/by/4.0/. The Creative Commons Public Domain Dedication waiver (http://creativecommons.org/publicdomain/zero/1.0/) applies to the data made available in this article, unless otherwise stated in a credit line to the data. 


\section{Background}

Borderline personality disorder (BPD) is a serious psychiatric disorder common among undergraduates, which is characterized by instability in emotion regulation, impulse control, interpersonal relationships, and self-image [1]. It is a significant contributor to self-harm and even suicide that results in a serious public health burden [2, 3]. BPD is highly prevalent among undergraduates. A recent meta-analysis including 40 studies showed that the prevalence of BPD in college samples ranged from 0.5 to $32.1 \%$ worldwide [4]. Another study showed that $15 \%$ of undergraduates screened positive for BPD in China [5].

\section{Childhood abuse and BPD features}

A multifactorial model suggested that the development of BPD, to a large extent, is an end product of childhood traumatic experiences such as emotional abuse, physical abuse and sexual abuse [6]. Additionally, researchers have found childhood abuse to be an important predictor of BPD in adolescence and adulthood [7-9]. Individuals who experienced childhood abuse tended to report higher scores for BPD features than those without that [9].

However, examining the effects of a specific subtype of childhood abuse on BPD features without controlling for the overlap between childhood abuse subtypes does not yield accurate results because most abused children have been exposed to multiple forms of abuse, which exhibit a high rate of co-occurrence $[10,11]$. Considering that previous studies have confirmed that among the different forms of childhood abuse, only emotional abuse was a unique predictor of BPD features [12-14], we hypothesized that only emotional abuse would be uniquely associated with BPD features when other forms of abuse were controlled (Hypothesis 1).

Furthermore, the potential mechanisms of how childhood abuse influences BPD features are unclear. We attempted to explore the potential mediators between childhood abuse and BPD features, which may provide some meaningful guidance for school staff and mental health professionals to prevent the development of BPD features. A growing number of studies have suggested that both resilience and selfesteem were significantly associated with childhood abuse and BPD features [15-31]. In light of the mediating role of self-esteem and resilience between childhood abuse and mental health problems [32-34], it was predicted that selfesteem and resilience might play a significant mediating role in the relationship between childhood abuse and BPD features.

\section{Self-esteem and resilience as mediators}

As suggested by the ecological systems theory, microsystem (e.g. family environment) was the most proximal factor of individual development [15]. Childhood abuse as a hostile environment for child that may threaten the ability to cope with risk or adversity and positive selfevaluations [16]. Extant research has demonstrated a strong negative relationship between childhood abuse and self-esteem [17-19], childhood abuse and resilience $[20,21]$; that is, the more childhood abuse an individual experienced, the lower his or her self-esteem and resilience. As an overall view of or feeling towards oneself as worthy or unworthy [22], self-esteem is beneficial for the development of human behavior, motivation, cognition, and emotion [23]. Sandler emphasizes that positive selfevaluation has a positive effect, whereas negative selfevaluation leads to a negative effect [16]. Furthermore, there were evidence suggesting that self-esteem may play a protective role against the development of BPD features [24-26].

Resilience, which refers to a dynamic system for the maintenance of positive adaptation in the face of trauma or adversity [27], may be another promising mediator of this relationship. High resilience has been proven to be linked to better health outcomes in the face of trauma or adversity, while low resilience has been found to lead to adverse consequences on an individual's mental health $[28,29]$. The emotional flexibility theory of resilience also suggests that resilient people can flexibly change their affective and physiological responses to match the demands of frequently changing environmental circumstances [30]; thus, high resilient people could successfully cope with adversity or risk and are less likely to have BPD features [31].

\section{Resilience and self-esteem}

Despite resilience and self-esteem are found to be closely related [35], there are still controversies about their relationship in the literature. Some studies found that resilience could exert a positive impact on the development of self-esteem, potentially through positive affect [36, 37]; Other studies, however, found that the levels of self-esteem could predict resilience [38, 39]. Based on the preceding rationale and previous findings, we hypothesized that resilience and self-esteem mediated the relationship between childhood abuse and BPD features (Hypothesis 2). Considering the uncertainty of the relationship between self-esteem and resilience, we establish three hypothesis models (Model A, Model B, Model C). Model A: two simple mediators (resilience and self-esteem) and one three-path mediator (resilience to self-esteem). Model B: two simple mediators (resilience and self-esteem) and one threepath mediator (self-esteem to resilience). Model C: two simple mediators (resilience and self-esteem).

The objectives of this study were to develop a better understanding of the mediating role of resilience and 
self-esteem in the development of BPD in the context of different types of childhood abuse in Chinese undergraduates. Understanding the role of self-esteem and resilience in the association between childhood abuse and BPD features may provide school staff and mental health professionals with a number of meaningful directions for preventing the development of BPD features.

\section{Methods}

\section{Participants and procedures}

A multistage stratification method was used to select participants. First, we randomly selected four universities from Anhui Province of China. Then, we randomly selected 2-5 classes for each grade in four schools, and excluded undergraduates under the age of 18. In total, 4287 undergraduates were invited to complete the questionnaires anonymously; of these undergraduates, 173 undergraduates refused to participate in this survey, and 54 undergraduates were absent. After removing 26 undergraduates who accidentally missed one or more tables of the questionnaire, 4034 undergraduates completed the questionnaire effectively (response rate: $94.1 \%$ ). The ethics committee of Anhui Medical University approved the study (No. 20180083). We obtained written informed consent from all participants after providing them with a complete and extensive description of the study.

\section{Measurements \\ The childhood trauma questionnaire-short form (CTQ-SF)}

The Chinese version of the CTQ-SF [40], a self-rating instrument with 28 items, was confirmed to assess traumatic experiences before the age of 16 among Chinese population reliably and validly. The frequency with which each event occurred is rated on a 5-point scale from 1 (never) to 5 (always), with higher scores indicating a higher rate of occurrence of abuse. The questionnaire is composed of five subscales: emotional abuse, physical abuse, sexual abuse, emotional neglect and physical neglect. As the focus of our study was childhood abuse, the emotional neglect and physical neglect subscales were omitted from the analyses. In this sample, the three subscales demonstrated good internal reliability (emotional abuse: $\alpha=0.81$; physical abuse: $\alpha=0.90$; sexual abuse: $\alpha=0.95$ ).

\section{The Connor-Davidson resilience scale (CD-RISC)}

The Chinese version of the 25-item CD-RISC has been confirmed to be a reliable and valid measurement in assessing resilience among Chinese adolescents [41]. Wu et al. 's four-factor model suggested that CD-RISC can be conceptually divided into four major domains: (1) tolerance for stress and goal orientation, (2) adaptability and acceptance of change, (3) optimism and sense of security, (4) trust in one's instinct [42]. Items are scored on a 5 -point scale $(0=$ not at all and $4=$ true nearly all of the time). The total score ranges from 0 to 100 , and higher summed scores reflect higher resilience. In this study, the Cronbach's a coefficient of the CD-RISC was 0.97 .

\section{The Rosenberg self-esteem scale (RSES)}

Participants completed the RSES [43], a self-report measure of self-esteem including 10 items (positively worded items and negatively worded items). Each item is rated on a 4-point scale ranging from 1 (strongly agree) to 4 (strongly disagree). Positively worded items are reverse scored; thus, higher total scores indicate a higher level of self-esteem. The Chinese version of the RSES was demonstrated to be validated among the Chinese population [44]. The Cronbach's $\alpha$ coefficient of the RSES was 0.84 , which indicated that it had good internal consistency in this sample.

\section{Mclean screening instrument for borderline personality disorder (MSI-BPD)}

BPD feature scores were measured using the MSI-BPD [45], which has been confirmed to have good validity and high internal consistency for Chinese adolescents [46]. According to Leung et al., MSI-BPD can be conceptually divided into three major domains: affect dysregulation, impulsivity, self and interpersonal disturbances [46]. The MSI-BPD comprises 10 items, each scored on a 2-point scale, with higher scores demonstrating higher severity of BPD features. In the current sample, high internal consistency of the measure was found $(\alpha=0.84)$.

\section{Statistical analysis}

The data analyses were performed using SPSS 21.0 and AMOS 24.0 statistical software. Spearman's correlation analysis was used to evaluate the correlations between variables. Then, structural equation modeling (SEM) was carried out to analyze the mediation effects. Based on the recommendations of Hooper et al. [47], a model was considered to have an acceptable fit if the comparative fit index (CFI) and Tucker-Lewis index (TLI) were 0.95 or above, the root mean square error of approximation (RMSEA) was less than 0.08 , and the $x^{2} /$ degrees of freedom $\left(\mathrm{X}^{2} / \mathrm{df}\right)$ was less than 5.00 .

\section{Results}

\section{Sociodemographic characteristics}

A total of 4034 students participated in the study, including 1070 (26.5\%) freshmen, 1048 (26.0\%) sophomores, 936 (23.2\%) juniors, 980 (24.3\%) seniors. The participants were aged between 18 and 23 years [mean $=$ 20.38, standard deviation $(\mathrm{SD})=1.35)$ ], and $1692(41.9 \%)$ were females (see Table 1). 
Table 1 Sociodemographic characteristics $(N=4034)$

\begin{tabular}{llll}
\hline Characteristics & & $\mathbf{n}$ & $\%$ \\
\hline Age (years) & Min-max & $18-23$ & \\
Gender & Mean (SD) & $20.38(1.35)$ & \\
& Male & 2342 & 58.1 \\
Area of family residence & Female & 1692 & 41.9 \\
& Urban & 1567 & 38.8 \\
Academic disciplines & Rural & 2467 & 61.2 \\
& Engineering & 993 & 24.6 \\
& Science & 961 & 23.8 \\
& Agriculture & 1046 & 25.9 \\
Grade & Medicine & 1034 & 25.6 \\
& Freshmen & 1070 & 26.5 \\
& Sophomores & 1048 & 26.0 \\
& Juniors & 936 & 23.2 \\
& Seniors & 980 & 24.3 \\
\hline
\end{tabular}

The correlated correlations between childhood abuse, self-esteem, resilience and BPD features

As shown in Table 2, BPD features were positively correlated with the three types of childhood abuse and negatively associated with self-esteem and resilience, while the three types of childhood abuse were negatively correlated with resilience and self-esteem $(P<0.001)$.

The mediating effects of resilience and self-esteem in the relationship between childhood abuse and BPD features

Each type of childhood abuse was entered into Model 1, Model 2, and Model 3 separately, and then all types of childhood abuse were simultaneously entered into one comprehensive model (Model 4). All variables were latent variables in our models. Using factorial algorithm to create separate item parcels for variables of emotional abuse, physical abuse, sexual abuse, and self-esteem [48]. Affect dysregulation, impulsivity, self and interpersonal disturbances were indicators of the latent variable of BPD features. Tolerance for stress and goal orientation, adaptability and acceptance of change, trust in one's

Table 2 Spearman correlations between all variables $(N=4034)$

\begin{tabular}{lllllll}
\hline & $\mathbf{1}$ & $\mathbf{2}$ & $\mathbf{3}$ & $\mathbf{4}$ & $\mathbf{5}$ & $\mathbf{6}$ \\
\hline 1 emotional abuse & - & & & & & \\
2 physical abuse & $0.47^{* *}$ & - & & & & \\
3 sexual abuse & $0.40^{* *}$ & $0.47^{* *}$ & - & & \\
4 resilience & $-0.19^{* *}$ & $-0.16^{* *}$ & $-0.13^{* *}$ & - & & \\
5 self-esteem & $-0.21^{* *}$ & $-0.16^{* *}$ & $-0.14^{* *}$ & $0.53^{* *}$ & - & \\
6 BPD features & $0.28^{* *}$ & $0.19^{* *}$ & $0.14^{* *}$ & $-0.31^{* *}$ & $-0.28^{* *}$ & - \\
\hline
\end{tabular}

${ }^{* *} P<0.001,{ }^{*} P<0.05$ instinct, optimism and sense of security were indicators of the latent variable of resilience (see Fig. 1). There was evidence that the data departed significantly from multivariate normality (Model 1 to Model 4, Mardia's coefficients were 210.163, 319.993, 623.714, 944.968) [49]; thus, these models were estimated with the maximum likelihood estimation, and fit statistics were corrected by using the Bollen-Stine bootstrapping procedure. Indirect
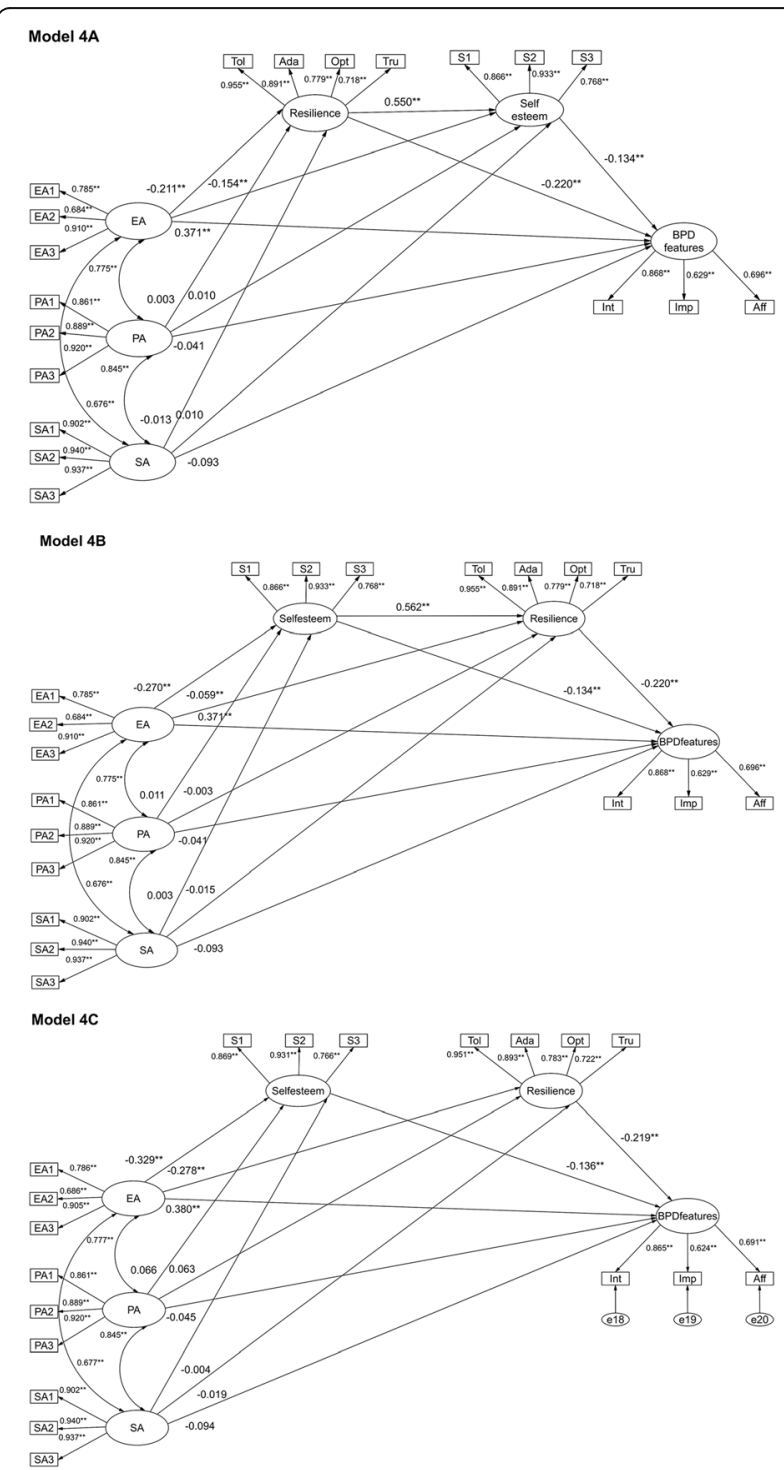

Fig. 1 The mediating effects of resilience and self-esteem when three types of childhood abuse were examined simultaneously (Model 4). Note. This figure depicts standardized regression weights. The first model is (4a), the second model is (4b) and the third model is (4c). EA emotional abuse, PA physical abuse, SA sexual abuse. Model fit indices for Model 4A and 4B: CFI $=0.997, \mathrm{TLI}=0.997$, RMSE $A=0.017, x^{2}=301.358, d f=137, x^{2} / d f=2.200$; Model fit indices for Model 4C: $\mathrm{CFI}=0.997, \mathrm{TLI}=0.997, \mathrm{RMSEA}=0.017, \mathrm{X}^{2}=302.809, \mathrm{df}=$ $138, X^{2} / \mathrm{df}=2.194 .{ }^{* *} P<0.001,{ }^{*} P<0.05$ 
effects and direct effects were tested by using biascorrected bootstrapping procedures $(5000$ bootstrap samples and 95\% confidence interval [CI]) $[50,51]$. The indirect effect or direct effect was considered to be statistically significant if the bias-corrected $95 \%$ CI did not include zero [52]. The SEM results showed that all of the models had good fits (see Fig. 1, Additional files 1, 2 and 3).

When childhood emotional abuse, physical abuse or sexual abuse was considered individually (see Additional files 1,2 and 3 for an illustration of Model 1, Model 2 and Model 3), the indirect effects and direct effects and their associated 95\% CIs are shown in Additional files 4, 5 and 6. All the indirect effects and direct effects were significant, indicating that resilience and self-esteem were mediators between these three types of childhood abuse and BPD features.

When these three types of abuse were considered simultaneously (see Fig. 1 for an illustration of Model 4), the indirect effects and direct effects and their associated 95\% CIs are shown in Table 3. Model 4A, Model 4B and Model $4 \mathrm{C}$ all showed that only the direct and indirect effects of emotional abuse on BPD features were significant (see Fig. 1 and Table 3). Consequently, when other forms of childhood abuse were controlled for, the indirect effects and direct effects of both physical abuse and sexual abuse were not found to be significant, and the association between emotional abuse and BPD features was partly mediated via resilience and self-esteem.

\section{Discussion}

The results of Model A, Model B and Model C were similar, indicating that no matter what the relationship between self-esteem and resilience is, self-esteem and resilience mediated the links between childhood abuse and BPD features, and emotional abuse is uniquely associated with BPD features. First, we found that after controlling for the overlap between the three types of childhood abuse, only emotional abuse was uniquely associated with BPD features, which may reflect the special effects of emotional abuse on the development of BPD features. This result was consistent with previous findings [12-14]. For example, Kuo et al. [14] found that only emotional abuse (and not other forms of abuse) was uniquely associated with the severity of BPD features and that difficulties with emotion regulation mediated the relationship when other forms of abuse were controlled.

It is logical that in an emotionally abusive rearing environment, individuals form a set of negative perceptions about themselves and fail to develop the ability that responding to changing environmental circumstances flexibly, as the experience of emotional abuse could directly convey a negative self-image that one is worthless, flawed, unloved or unwanted [53]. It is unsurprising that emotional abuse subsequently affects the healthy development of personality and leads to BPD features. Therefore, we could infer from our results that emotional abuse has a more pronounced impact on personality health development than physical abuse or sexual abuse, which is consistent with previous research showing that emotional abuse is central to childhood abuse and may be more harmful than other forms of abuse [32, 53-55]. Compared to other forms of abuse, emotional abuse was found to result in a higher risk of developing mental disorders and psychological symptoms $[32,55]$.

Second, the mediation analysis showed that the association between emotional abuse and BPD features was partially mediated by resilience, self-esteem. Emotional abuse had not only a direct impact on BPD features but also an indirect impact via resilience and self-esteem. This finding is in line with numerous previous studies that self-esteem and resilience could mediate the relationship between childhood emotional abuse and mental health problems, such as emotional and behavioral problems, adulthood psychopathology, and psychological symptoms [32-34]. Base on the emotional flexibility theory, high resilience can help people flexibly change their affective and physiological responses, as reflected in a low level of emotional variability [30]. On the contrary, a high level of emotional variability is a hallmark of BPD symptoms [56]. Self-esteem could serve as a positive functioning dimension that helps adolescents manage, regulate, and minimize their psychological distress to build higher levels of subjective happiness, which is beneficial for their mental health [57]. The diathesisstress model suggests that the more vulnerable the person, the less environmental stress was required to develop BPD features [58]. The results of our study confirm this model and prove that low resilience and self-esteem would promote the development of BPD features.

\section{Limitations}

Although our study has a number of strengths, including the large sample size, the adoption of a random sampling approach and the separate and simultaneous testing of three types of childhood abuse, our study has several limitations. First, given that the cross-sectional design of our study can't provide time-ordering of resilience, self-esteem, and BPD features, there may be other models [59]. Future prospective researches are required to explore the relationship between childhood abuse, resilience, self-esteem, and BPD features. Second, childhood abuse, resilience, self-esteem, and BPD features were assessed by self-report; thus, recall bias was inevitable. Third, the sociodemographic variables such as age, gender, area of family residence, grade and academic 
Table 3 Indirect and direct effects of childhood abuse on BPD features - three types of childhood abuse examined simultaneously (Model 4)

\begin{tabular}{|c|c|c|c|c|}
\hline Model pathway & Estimate & SE & lower & upper \\
\hline \multicolumn{5}{|c|}{$\begin{array}{l}\text { Model } 4 \mathrm{~A} \text { - Three types of childhood abuse, two simple mediators (resilience and self-esteem) and one three-path mediator (resilience to self- } \\
\text { esteem) }\end{array}$} \\
\hline $\mathrm{EA} \rightarrow$ resilience $\rightarrow$ BPD features & $0.046^{* *}$ & 0.009 & 0.031 & 0.064 \\
\hline EA $\rightarrow$ self-esteem $\rightarrow$ BPD features & $0.021^{* *}$ & 0.005 & 0.013 & 0.032 \\
\hline EA $\rightarrow$ resilience $\rightarrow$ self-esteem $\rightarrow$ BPD features & $0.016^{* *}$ & 0.004 & 0.009 & 0.024 \\
\hline $\mathrm{EA} \rightarrow \mathrm{BPD}$ features & $0.371^{* *}$ & 0.044 & 0.289 & 0.458 \\
\hline $\mathrm{PA} \rightarrow$ resilience $\rightarrow$ BPD features & -0.001 & 0.009 & -0.019 & 0.018 \\
\hline $\mathrm{PA} \rightarrow$ self-esteem $\rightarrow$ BPD features & -0.001 & 0.006 & -0.012 & 0.010 \\
\hline $\mathrm{PA} \rightarrow$ resilience $\rightarrow$ self-esteem $\rightarrow$ BPD features & 0.000 & 0.003 & -0.007 & 0.006 \\
\hline $\mathrm{PA} \rightarrow \mathrm{BPD}$ features & -0.041 & 0.057 & -0.152 & 0.071 \\
\hline $\mathrm{SA} \rightarrow$ resilience $\rightarrow$ BPD features & 0.003 & 0.009 & -0.014 & 0.019 \\
\hline $\mathrm{SA} \rightarrow$ self-esteem $\rightarrow$ BPD features & -0.001 & 0.005 & -0.012 & 0.008 \\
\hline $\mathrm{SA} \rightarrow$ resilience $\rightarrow$ self-esteem $\rightarrow$ BPD features & 0.001 & 0.003 & -0.005 & 0.007 \\
\hline $\mathrm{SA} \rightarrow \mathrm{BPD}$ features & -0.093 & 0.048 & -0.187 & 0.004 \\
\hline
\end{tabular}

Model 4B - Three types of childhood abuse, two simple mediators (resilience and self-esteem) and one three-path mediator (self-esteem to resilience)

\begin{tabular}{|c|c|c|c|c|}
\hline $\mathrm{EA} \rightarrow$ resilience $\rightarrow$ BPD features & $0.013^{*}$ & 0.006 & 0.001 & 0.025 \\
\hline $\mathrm{EA} \rightarrow$ self-esteem $\rightarrow$ BPD features & $0.036^{* *}$ & 0.008 & 0.024 & 0.053 \\
\hline $\mathrm{EA} \rightarrow$ self-esteem $\rightarrow$ resilience $\rightarrow$ BPD features & $0.033^{* *}$ & 0.006 & 0.023 & 0.046 \\
\hline $\mathrm{EA} \rightarrow \mathrm{BPD}$ features & $0.371^{* *}$ & 0.044 & 0.289 & 0.458 \\
\hline $\mathrm{PA} \rightarrow$ resilience $\rightarrow$ BPD features & 0.001 & 0.008 & -0.014 & 0.017 \\
\hline $\mathrm{PA} \rightarrow$ self-esteem $\rightarrow$ BPD features & -0.001 & 0.007 & -0.014 & 0.012 \\
\hline $\mathrm{PA} \rightarrow$ self-esteem $\rightarrow$ resilience $\rightarrow$ BPD features & -0.001 & 0.006 & -0.013 & 0.011 \\
\hline $\mathrm{PA} \rightarrow \mathrm{BPD}$ features & -0.041 & 0.057 & -0.152 & 0.071 \\
\hline $\mathrm{SA} \rightarrow$ resilience $\rightarrow$ BPD features & 0.003 & 0.008 & -0.013 & 0.019 \\
\hline $\mathrm{SA} \rightarrow$ self-esteem $\rightarrow$ BPD features & 0.000 & 0.005 & -0.012 & 0.010 \\
\hline $\mathrm{SA} \rightarrow$ self-esteem $\rightarrow$ resilience $\rightarrow$ BPD features & 0.000 & 0.005 & -0.010 & 0.009 \\
\hline $\mathrm{SA} \rightarrow \mathrm{BPD}$ features & -0.093 & 0.048 & -0.187 & 0.004 \\
\hline
\end{tabular}

Model $4 C$ - Three types of childhood abuse, two simple mediators (resilience and self-esteem)

\begin{tabular}{|c|c|c|c|c|}
\hline $\mathrm{EA} \rightarrow$ resilience $\rightarrow$ BPD features & $0.061^{* *}$ & 0.012 & 0.041 & 0.086 \\
\hline EA $\rightarrow$ self-esteem $\rightarrow$ BPD features & $0.045^{* *}$ & 0.010 & 0.029 & 0.067 \\
\hline $\mathrm{EA} \rightarrow \mathrm{BPD}$ features & $0.380^{* *}$ & 0.046 & 0.295 & 0.472 \\
\hline $\mathrm{PA} \rightarrow$ resilience $\rightarrow$ BPD features & -0.014 & 0.015 & -0.047 & 0.013 \\
\hline $\mathrm{PA} \rightarrow$ self-esteem $\rightarrow$ BPD features & -0.009 & 0.010 & -0.030 & 0.010 \\
\hline $\mathrm{PA} \rightarrow \mathrm{BPD}$ features & -0.045 & 0.058 & -0.160 & 0.070 \\
\hline $\mathrm{SA} \rightarrow$ resilience $\rightarrow$ BPD features & 0.004 & 0.011 & -0.017 & 0.026 \\
\hline $\mathrm{SA} \rightarrow$ self-esteem $\rightarrow$ BPD features & 0.000 & 0.007 & -0.014 & 0.014 \\
\hline $\mathrm{SA} \rightarrow \mathrm{BPD}$ features & -0.094 & 0.049 & -0.190 & 0.005 \\
\hline
\end{tabular}

$E A$ emotional abuse, $P A$ physical abuse, SA sexual abuse, SE Standard Error, lower lower bound of $95 \%$ confidence interval, upper upper bound of $95 \%$ confidence interval. ${ }^{* *} P<0.001,{ }^{*} P<0.05$

disciplines were not included in these models, in other words, we did not control for the sociodemographic variables. Fourth, only four universities in one city were included in this study, so the conclusions cannot be extended to all college students in China.

\section{Conclusions}

Firstly, the findings of our research provide valuable insight into the relationship between childhood abuse, self-esteem, resilience, and BPD features among Chinese college students. Secondly, our study provides novel 
evidence that emotional abuse was uniquely associated with BPD features. Thirdly, our study provides novel evidence that self-esteem and resilience are important protective factors between childhood abuse and BPD features. To our knowledge, our study is the first study to investigate the mechanism of the relationship among childhood abuse, resilience, self-esteem and BPD features, thus our research fills the gap in this field and expands the relationship between childhood abuse and BPD features. Furthermore, our study could provide school staff and mental health professionals with a number of meaningful guidance. For example, given our finding that self-esteem and resilience may be important intervention factors for controlling the development of BPD features in the context of childhood abuse, school staff and mental health professionals could consider improving an individual's resilience and self-esteem to control the development of BPD features. Likewise, our finding that emotional abuse uniquely relates to BPD features suggests great importance should be attached to emotionally abused victims.

\section{Abbreviations}

BPD: Borderline personality disorder; SEM: Structural equation modeling; EA: Emotional abuse; PA: Physical abuse; SA: Sexual abuse; CTQ-

SF: Childhood Trauma Questionnaire-Short Form; MSI-BPD: Mclean Screening Instrument for Borderline Personality Disorder; CD-RISC: ConnorDavidson Resilience Scale; RSES: Rosenberg Self-Esteem Scale

\section{Supplementary Information}

The online version contains supplementary material available at https://doi. org/10.1186/s12888-021-03332-w.

\section{Additional file 1. \\ Additional file 2. \\ Additional file 3. \\ Additional file 4. \\ Additional file 5 . \\ Additional file 6.}

\section{Acknowledgements}

We are extremely grateful to all of the participants.

\section{Authors' contributions}

PS, DX and JC contributed to the concept and design of the study; MY, YH and SC collected the data; DX and GW performed the statistical analyses; DX, JC and PS wrote and revised the manuscript; and PS obtained funding and supervised the study. All authors read and approved the final version of the manuscript.

\section{Funding}

This work was supported by the grants from the National Nature Science Foundation of China (Grants No. 81874268). The funding body had no role in the design of the study and collection, analysis, and interpretation of data and in writing the manuscript.

\section{Availability of data and materials}

All data and materials related to the study are available from the corresponding author upon reasonable request.

\section{Declarations}

\section{Ethics approval and consent to participate}

The study was approved by the Biomedicine Ethical Committee of Anhui Medical University (No. 20180083). All the invited participants provided verbal and written informed consent before the research began.

\section{Consent for publication}

Not applicable.

\section{Competing interests}

The authors declare that they have no competing interests.

\section{Author details}

${ }^{1}$ Department of Maternal, Child and Adolescent Health, School of Public Health, Anhui Medical University, No.81 Meishan Road, Hefei 230032, Anhui, China. ${ }^{2}$ Anhui Provincial Center for Disease Control and Prevention, No.12560 Fanhua Avenue, Hefei 230601, Anhui, China. ${ }^{3}$ Key Laboratory of Population Health Across Life Cycle (Anhui Medical University), Ministry of Education of the People's Republic of China, No 81 Meishan Road, Hefei 230032, Anhui, China. ${ }^{4}$ Anhui Provincial Key Laboratory of Population Health and Aristogenics, No 81 Meishan Road, Hefei 230032, Anhui, China.

Received: 24 June 2020 Accepted: 18 June 2021

Published online: 01 July 2021

\section{References}

1. Krause-Utz A, Erol E, Brousianou AV, Cackowski S, Paret C, Ende G, et al. Selfreported impulsivity in women with borderline personality disorder: the role of childhood maltreatment severity and emotion regulation difficulties. Border Pers Dis Emot. 2019;6(1):6. https://doi.org/10.1186/s40479-019-0101-8.

2. Leichsenring F, Leibing E, Kruse J, New AS, Leweke F. Borderline personality disorder. Lancet. 2011;377(9759):74-84. https://doi.org/10.1016/S0140-6736(1 0)61422-5.

3. Lereya ST, Winsper C, Tang NK, Wolke D. Sleep problems in childhood and borderline personality disorder symptoms in early adolescence. J Abnorm Child Psychol. 2017;45(1):193-206. https://doi.org/10.1007/s10802-016-01 58-4.

4. Meaney R, Hasking P, Reupert A. Prevalence of borderline personality disorder in university samples: systematic review, meta-analysis and metaregression. PLoS One. 2016;11(5):e0155439. https://doi.org/10.1371/journal. pone.0155439.

5. Yang $H$, Lei $X$, Zhong $M$, Zhou Q, Ling $Y$, Jungkunz $M$, et al. Psychometric properties of the Chinese version of the brief borderline symptom list in undergraduate students and clinical patients. Front Psychol. 2018;9:605. https://doi.org/10.3389/fpsyg.2018.00605.

6. Zanarini MC, Frankenburg FR. Emotional hypochondriasis, hyperbole, and the borderline patient. J Psychother Pract Res. 1994;3(1):25-36.

7. Ibrahim J, Cosgrave N, Woolgar M. Childhood maltreatment and its link to borderline personality disorder features in children: a systematic review approach. Clin Child Psychol Psychiatry. 2018;23(1):57-76. https://doi.org/1 $0.1177 / 1359104517712778$.

8. Cirasola A, Hillman S, Fonagy P, Chiesa M. Mapping the road from childhood adversity to personality disorder: the role of unresolved states of mind. Personal Ment Health. 2017;11(2):77-90. https://doi.org/10.1002/ pmh.1365.

9. Hecht KF, Cicchetti D, Rogosch FA, Crick NR. Borderline personality features in childhood: the role of subtype, developmental timing, and chronicity of child maltreatment. Dev Psychopathol. 2014;26(3):805-15. https://doi.org/1 $0.1017 /$ S0954579414000406.

10. Teicher MH, Samson JA, Polcari A, McGreenery CE. Sticks, stones, and hurtful words: relative effects of various forms of childhood maltreatment. Am J Psychiatry. 2006;163(6):993-1000. https://doi.org/10.1176/ajp.2006.163.6.993.

11. Sesar K, Zivcić-Bećirević I, Sesar D. Multi-type maltreatment in childhood and psychological adjustment in adolescence: questionnaire study among adolescents in Western Herzegovina Canton. Croat Med J. 2008;49(2):24356. https://doi.org/10.3325/cmj.2008.2.243.

12. Rosenstein LK, Ellison WD, Walsh E, Chelminski I, Dalrymple K, Zimmerman $M$. The role of emotion regulation difficulties in the connection between childhood emotional abuse and borderline personality features. Personal Disord. 2018;9(6):590-4. https://doi.org/10.1037/per0000294. 
13. Allen B. An analysis of the impact of diverse forms of childhood psychological maltreatment on emotional adjustment in early adulthood. Child Maltreat. 2008;13(3):307-12. https://doi.org/10.1177/10775595083183 94.

14. Kuo JR, Khoury JE, Metcalfe R, Fitzpatrick S, Goodwill A. An examination of the relationship between childhood emotional abuse and borderline personality disorder features: the role of difficulties with emotion regulation. Child Abuse Negl. 2015;39:147-55. https://doi.org/10.1016/j.chiabu.2014.08. 008.

15. Bronfenbrenner U. Ecological system theory. Ann Child Dev. 1989;6:187-249.

16. Sandler I. Quality and ecology of adversity as common mechanisms of risk and resilience. Am J Community Psychol. 2001;29(1):19-61. https://doi.org/1 0.1023/A:1005237110505.

17. Berber CC, Odacı H. Does child abuse have an impact on self-esteem, depression, anxiety and stress conditions of individuals. Int J Soc Psychiatry. 2020;66(2):171-8. https://doi.org/10.1177/0020764019894618.

18. Mwakanyamale AA, Yizhen Y. Psychological maltreatment and its relationship with self-esteem and psychological stress among adolescents in Tanzania: a community based, cross-sectional study. BMC Psychiatry. 2019;19(1):176. https://doi.org/10.1186/s12888-019-2139-y.

19. Mwakanyamale AA, Wande DP, Yizhen Y. Multi-type child maltreatment: prevalence and its relationship with self-esteem among secondary school students in Tanzania. BMC Psychol. 2018;6(1):35. https://doi.org/10.1186/s403 59-018-0244-1.

20. Kesebir S, Ünübol B, Tatıdil Yaylacı E, Gündoğar D, Ünübol H. Impact of childhood trauma and affective temperament on resilience in bipolar disorder. Int J Bipolar Disord. 2015;3(1):3. https://doi.org/10.1 186/s40345-0150023-3.

21. Wei J, Shi J, Zhang M, Ding H, Kang C, Wang K, et al. Childhood trauma and its correlation with resilience among primary and middle school students in Wuhan city in 2015. Wei Sheng Yan Jiu. 2019;48(5):717-27.

22. Cast AD, Burke PJ. A theory of self-esteem. Social Forces. 2002;80(3):1041-68. https://doi.org/10.1353/sof.2002.0003.

23. Winter $\mathrm{D}$, Bohus $\mathrm{M}$, Lis $\mathrm{S}$. Understanding negative self-evaluations in borderline personality disorder-a review of self-related cognitions, emotions, and motives. Curr Psychiatry Rep. 2017;19(3):17. https://doi.org/10.1007/s11 920-017-0771-0

24. Vater A, Schröder-Abé M, Schütz A, Lammers CH, Roepke S. Discrepancies between explicit and implicit self-esteem are linked to symptom severity in borderline personality disorder. J Behav Ther Exp Psychiatry. 2010;41(4):35764. https://doi.org/10.1016/j.jbtep.2010.03.007.

25. Bungert M, Liebke L, Thome J, Haeussler K, Bohus M, Lis S. Rejection sensitivity and symptom severity in patients with borderline personality disorder: effects of childhood maltreatment and self-esteem. Borderline Personal Disord Emot Dysregul. 2015;2(1):4. https://doi.org/10.1186/s40479015-0025-x.

26. Winter D, Steeb L, Herbert C, Sedikides C, Schmahl C, Bohus M, et al. Lower self-positivity and its association with self-esteem in women with borderline personality disorder. Behav Res Ther. 2018;109:84-93. https://doi.org/10.101 6/j.brat.2018.07.008.

27. Wingo AP, Wrenn G, Pelletier T, Gutman AR, Bradley B, Ressler KJ. Moderating effects of resilience on depression in individuals with a history of childhood abuse or trauma exposure. J Affect Disord. 2010;126(3):411-4. https://doi.org/10.1016/j.jad.2010.04.009.

28. Rutter M. Implications of resilience concepts for scientific understanding. Ann N Y Acad Sci. 2006;1094(1):1-12. https://doi.org/10.1196/annals.1376.002.

29. Kilpatrick LA, Istrin JJ, Gupta A, Naliboff BD, Tillisch K, Labus JS, et al. Sex commonalities and differences in the relationship between resilient personality and the intrinsic connectivity of the salience and default mode networks. Biol Psychol. 2015;112:107-15. https://doi.org/10.1016/j. biopsycho.2015.09.010.

30. Waugh CE, Thompson RJ, Gotlib $\mathbb{H}$. Flexible emotional responsiveness in trait resilience. Emotion. 2011;11(5):1059-67. https://doi.org/10.1037/a0021786.

31. Kim MK, Kim JS, Park HI, Choi SW, Oh WJ, Seok JH. Early life stress, resilience and emotional dysregulation in major depressive disorder with comorbid borderline personality disorder. J Affect Disord. 2018;236:113-9. https://doi. org/10.1016/j.jad.2018.04.119.

32. Wang $S$, Xu H, Zhang S, Yang R, Li D, Sun Y, et al. Linking childhood maltreatment and psychological symptoms: the role of social support, coping styles, and self-esteem in adolescents. J Interpers Violence. 2020; 886260520918571
33. Arslan G. Psychological maltreatment, emotional and behavioral problems in adolescents: the mediating role of resilience and self-esteem. Child Abuse Negl. 2016:52:200-9. https://doi.org/10.1016/j.chiabu.2015.09.010.

34. Finzi-Dottan R, Karu T. From emotional abuse in childhood to psychopathology in adulthood: a path mediated by immature defense mechanisms and self-esteem. J Nerv Ment Dis. 2006;194(8):616-21. https:// doi.org/10.1097/01.nmd.0000230654.49933.23.

35. Yan H, Li X, Li J, Wang W, Yang Y, Yao X, et al. Association between perceived HIV stigma, social support, resilience, self-esteem, and depressive symptoms among HIV-positive men who have sex with men (MSM) in Nanjing, China. AIDS Care. 2019;31(9):1069-76. https://doi.org/10.1080/0954 0121.2019.1601677.

36. Benetti C, Kambouropoulos N. Affect-regulated indirect effects of trait anxiety and trait resilience on self-esteem. Elsevier. 2006;41(2):341-52.

37. Liu Y, Wang Z, Zhou C, Li T. Affect and self-esteem as mediators between trait resilience and psychological adjustment. Personal Individ Differ. 2014; 66:92-7. https://doi.org/10.1016/j.paid.2014.03.023.

38. Tras Z, Arslan C, Hamarta E. An examination of resilience in university students in terms of self-esteem and social self-efficacy. Int J Acad Res. 2013;5(3):325-30. https://doi.org/10.7813/2075-4124.2013/5-3/B.49.

39. Scoglio AA, Rudat DA, Garvert $D$, Jarmolowski $M$, Jackson $C$, Herman JL. Selfcompassion and responses to trauma: the role of emotion regulation. J Interpers Violence. 2018;33(13):2016-36. https://doi.org/10.1177/0886260515622296.

40. He J, Zhong X, Gao Y, Xiong G, Yao S. Psychometric properties of the Chinese version of the childhood trauma questionnaire-short form (CTQ-SF) among undergraduates and depressive patients. Child Abuse Negl. 2019;91: 102-8. https://doi.org/10.1016/j.chiabu.2019.03.009.

41. Yu XN, Lau JT, Mak WW, Zhang J, Lui WW, Zhang J. Factor structure and psychometric properties of the Connor-Davidson resilience scale among Chinese adolescents. Compr Psychiatry. 2011;52(2):218-24. https://doi.org/1 0.1016/j.comppsych.2010.05.010.

42. Wu L, Tan Y, Liu Y. Factor structure and psychometric evaluation of the Connor-Davidson resilience scale in a new employee population of China. BMC Psychiatry. 2017;17(1):49. https://doi.org/10.1186/s12888-017-1219-0.

43. Rosenberg M. Society and the adolescent self-image. Princeton. 1965;3(2): 1780-90.

44. Wei J, Zhang JF, Mao XZ. Psychometric properties of Rosenberg self-esteem scale-revised for middle school students. Chin J Clin Psychol. 2018;26(04): 629-37.

45. Zanarini MC, Vujanovic AA, Parachini EA, Boulanger JL, Frankenburg FR, Hennen J. A screening measure for BPD: the McLean screening instrument for borderline personality disorder (MSI-BPD). J Personal Disord. 2003;17(6): 568-73. https://doi.org/10.1521/pedi.17.6.568.25355.

46. Leung SW, Leung F. Construct validity and prevalence rate of borderline personality disorder among Chinese adolescents. J Personal Disord. 2009; 23(5):494-513. https://doi.org/10.1521/pedi.2009.23.5.494.

47. Hooper D, Coughlan J, Mullen MR. Structural equation modelling: guidelines for determining model fit. Electron J Business Res Methods. 2008;6(1):53-60.

48. Rogers WM, Schmitt N. Parameter recovery and model fit using multidimensional composites: a comparison of four empirical parceling algorithms. Multivar Behav Res. 2004;39(3):379-412. https://doi.org/10.1207/ S15327906MBR3903_1.

49. Gao S, Mokhtarian PL, Johnston RA. Nonnormality of data in structural equation models. Transportation Res Record J Transportation Res Board. 2008;2082(1):116-24. https://doi.org/10.3141/2082-14.

50. Kim H, Millsap R. Using the Bollen-Stine bootstrapping method for evaluating approximate fit indices. Multivar Behav Res. 2014;49(6):581-96. https://doi.org/10.1080/00273171.2014.947352.

51. Bollen KA, Stine R. Bootstrapping goodness of fit measures in structural equation models. Sociol Methods Res. 1992;21(2):205-29. https://doi.org/1 $0.1177 / 0049124192021002004$.

52. MacKinnon DP, Lockwood CM, Hoffman JM, West SG, Sheets V. A comparison of methods to test mediation and other intervening variable effects. Psychol Methods. 2002;7(1):83-104. https://doi.org/10.1037/1082-989X.7.1.83.

53. Spertus IL, Yehuda R, Wong CM, Halligan S, Seremetis SV. Childhood emotional abuse and neglect as predictors of psychological and physical symptoms in women presenting to a primary care practice. Child Abuse Negl. 2003;27(11):1247-58. https://doi.org/10.1016/j.chiabu.2003.05.001.

54. Hart SN, Brassard MR. A major threat to children's mental health. Psychological maltreatment. Am Psychol. 1987;42(2):160-5. https://doi.org/1 0.1037/0003-066X.42.2.160 
55. Norman RE, Byambaa M, De R, Butchart A, Scott J, Vos T. The long-term health consequences of child physical abuse, emotional abuse, and neglect: a systematic review and meta-analysis. PLoS Med. 2012;9(11):e1001349. https://doi.org/10.1371/journal.pmed.1001349.

56. Trull TJ, Solhan MB, Tragesser SL, Jahng S, Wood PK, Piasecki TM, et al. Affective instability: measuring a core feature of borderline personality disorder with ecological momentary assessment. J Abnorm Psychol. 2008; 117(3):647-61. https://doi.org/10.1037/a0012532.

57. Freire T, Ferreira G. Do I need to be positive to be happy? Considering the role of self-esteem, life satisfaction, and psychological distress in Portuguese adolescents' subjective happiness. Psychol Rep. 2019;33294119846064.

58. Zanarini MC, Frankenburg FR. Pathways to the development of borderline personality disorder. J Personal Disord. 1997;11(1):93-104. https://doi.org/1 0.1521/pedi.1997.11.1.93

59. Tate CU. On the overuse and misuse of mediation analysis: it may be a matter of timing. Basic Appl Soc Psychol. 2015;37(4):235-46. https://doi. org/10.1080/01973533.2015.1062380.

\section{Publisher's Note}

Springer Nature remains neutral with regard to jurisdictional claims in published maps and institutional affiliations.

Ready to submit your research? Choose BMC and benefit from:

- fast, convenient online submission

- thorough peer review by experienced researchers in your field

- rapid publication on acceptance

- support for research data, including large and complex data types

- gold Open Access which fosters wider collaboration and increased citations

- maximum visibility for your research: over $100 \mathrm{M}$ website views per year

At $\mathrm{BMC}$, research is always in progress.

Learn more biomedcentral.com/submissions 